\title{
Acceptability of screening for pregnancy intention in general practice: a population survey of people of reproductive age
}

\section{CURRENT STATUS: UNDER REVIEW}

BMC Family Practice $\triangle$ BMC series

Karin Hammarberg

Victorian Assisted Reproductive Treatment Authority

varin.hammarberg@monash.eduCorresponding Author

ORCiD: https://orcid.org/0000-0002-5988-5865

Julie Hassard

Victorian Assisted Reproductive Treatment Authority

Renee de Silva

Victorian Assisted Reproductive Treatment Authority

Louise Johnson

Victorian Assisted Reproductive Treatment Authority

DOI:

10.21203/rs.2.19064/v1

\section{SUBJECT AREAS}

General Practice Sexual \& Reproductive Medicine

\section{KEYWORDS}

preconception health, preconception care, health promotion, pregnancy intention, general practice, primary care 
Abstract

Background: Optimal parental preconception health benefits reproductive outcomes. However, preconception health promotion is not routinely offered in primary health care settings to people of reproductive age. The aim was to gauge the planned preconception health behaviours and attitudes towards being asked about pregnancy intention by a general practitioner (GP) among people of reproductive age in Australia.

Method: The research was conducted on a single wave of Australia's first and only probability-based online panel, Life in Australia ${ }^{\mathrm{TM}}$. Members of the Life in Australia ${ }^{\mathrm{TM}}$ panel are Australian residents aged 18 years or over. All active members between the ages of 18 and 45 years were eligible to participate. Eligible panel members were invited to complete a survey about fertility and childbearing. Data were collected from 18 February to 4 March 2019.

Results: In all 965 female and male members of Life in Australia ${ }^{\mathrm{TM}}$ aged between 18 and 45 years were invited to complete the survey. Of these, $716(74.2 \%)$ agreed. Most respondents indicated that if they were planning to have a child they would try to optimise their preconception health by adopting a healthier diet (80\%), seeing a GP for a health check-up (78\%), reducing alcohol consumption (78\% of those consuming alcohol), getting fitter (73\%), and stopping smoking (70\% of smokers). Three in four $(74 \%)$ stated that they would not mind if their GP asked them about their pregnancy intentions. Conclusion: Findings suggests that routinely asking people of reproductive age about their pregnancy intentions and advising those who are planning pregnancy about what they can do to ensure optimal preconception health would be acceptable to most people and may improve reproductive outcomes. Full Text

Due to technical limitations, full-text HTML conversion of this manuscript could not be completed. However, the manuscript can be downloaded and accessed as a PDF. 